\title{
Response to a smoking cessation workshop by family practice resident physicians
}

\author{
Charles Alvin Jones
}

\begin{abstract}
Objective - To determine the effectiveness of a smoking cessation workshop to train resident physicians to apply smoking cessation techniques to their patients. Design-Retrospective review of patients' notes after physicians had participated in a three-hour workshop on smoking cessation and patients' notes had been flagged to prompt physicians to ask about smoking status.
\end{abstract}

Setting-Family practice clinic of a university-based family medicine residency programme.

Subjects-Nineteen resident physicians and 149 patient records.

Main outcome measures-Physicians' response to patients who smoke in $(a)$ giving advice to stop smoking, (b) establishing a date to stop smoking, and (c) making referrals for psychological counselling.

Results-Comparison of 46 patient records before the workshop and 57 identified two months after the workshop showed that resident physicians' sensitivity to patients' smoking status, especially in offering advice about smoking, increased initially after the workshop ( $p<0.001)$. Estảblishing a date to stop smoking and making psychological referrals also increased, though not significantly (stopping date, $p<0.085$; referral, $p<0.149)$. However, none of the three behaviours was sustained over time. A comparison of the pre-workshop records with 46 records identified six months after the workshop showed that none of the outcome measures showed significant differences, and psychological referrals actually decreased.

Conclusions - A single three-hour training workshop on counselling techniques for stopping smoking and the flagging of patients' notes to prompt physicians to ask about smoking are not sufficient to produce a sustained effect over a sixmonth period. Successful integration of appropriate physician behaviours into a practice requires systems that reinforce the involvement of physicians and use techniques that help physicians internalise health promotion with their smoking patients.

(Tobacco Control 1993; 2: 30-34)

\section{Introduction}

Although most physicians agree with the US Surgeon General's recommendation regarding the importance of smoking cessation, only $3 \%$ of primary care physicians believe that they are very successful in helping patients to stop smoking. ${ }^{1}$ The American Cancer Society (ACS) found in 1989 that most US physicians agreed with ACS recommendations, but only $50 \%$ were following ACS guidelines. ${ }^{2}$ In another survey, over half of the primary care physicians believed that eliminating cigarette smoking was very important, but only onequarter of the physicians had asked about their patients' smoking status. ${ }^{1}$ Still another survey found that only $58 \%$ of healthy smokers and $50 \%$ of smokers with smoking-related symptoms reported that they were advised by their physicians to quit smoking. ${ }^{3}$

Smoking-attributable mortality is the second leading cause of years of potential life lost. ${ }^{4}$ This is one area where family physicians' involvement could produce an improved quality of life and a prolonged life expectancy for patients. Approximately 35 million Americans who smoke consult their primary physician at least once annually. ${ }^{5}$ If only $10 \%$ of these patients stopped smoking due to physician counselling, then 3.5 million smokers would quit. If one assumes that $40 \%$ of smokers ultimately die of diseases caused by smoking, ${ }^{6}$ this reduction in smoking could prevent more than one million premature smoking-attributable deaths.

Family physicians are ideally situated to promote effective smoking cessation. Of the 50 million Americans who smoke, $90 \%$ would like to quit, and most are concerned about health hazards of cigarette smoking. ${ }^{7}$ Just as primary care physicians are a respected source of health information, ${ }^{8} 75 \%$ of smokers felt that their physician's advice would be "somewhat" to "very" effective in getting them to stop smoking. ${ }^{9}$ Studies conducted to assess the primary care physicians' role in counselling and assisting smokers to stop smoking indicate that such involvement produces a quit rate that varies from $5 \%$ to $30 \% \cdot{ }^{10-14}$ On the other hand the average annual quit rate for persons who attempt the process without physician involvement is approximately $3 \%$. Kottke's meta-analysis of 39 controlled smoking-cessation trials showed that effective smoking cessation techniques can be applied in a busy family physician's practice. ${ }^{15}$

Despite the proven effectiveness of physician involvement and despite their stated beliefs, 
however, physicians are failing to instruct their patients to stop smoking, even though they believe that smoking is a health hazard. ${ }^{9}$ The growth of Doctors Ought to Care (DOC) chapters in medical schools and residency programmes throughout the US suggests that physicians in training are interested in taking a pro-active approach to educating their patients about such hazards. ${ }^{16}$ Physicians must be motivated to act upon their convictions, however, and give active smoking-cessation instructions to their patients. One method that has been used extensively to teach resident physicians about smoking cessation techniques is the short workshop conference. The effectiveness of such conferences, especially in promoting long-term physician behaviours that help patients become non-smokers, has not been assessed. Most studies that have assessed the effectiveness of workshops and similar training modes have concentrated on residents' learned counselling skills, rather than the application of those skills to individual patient care. This study, on the other hand, evaluated resident physicians' short- and long-term implementation of intervention behaviour following a cigarette-smoking cessation workshop.

5

\author{
workshop covering smoking cessation tech- \\ niques. Nineteen residents (four first-year, \\ eight second-year, and seven third-year) \\ participated in the workshop, which was \\ Methods \\ In January, the family practice residents at \\ Texas Tech University Health Sciences
}

delivered as one of the regular, mandatory weekly conferences attended by residents in the programme. The presentation of material was similar to the information provided by the American Academy of Family Physicians smoking-cessation $\mathrm{kit}^{18}$ and incorporated the multiple-intervention strategies discussed by Kottke. ${ }^{15}$

The presentation, conducted by a faculty family physician and a psychologist, included 1) a 1-hour didactic lecture with slide presentation of the impact on health of cigarette smoking, 2) a second hour dedicated to instruction for prescribing nicotine polacrilex gum and effective counselling strategies, and 3) videotaped case presentations demonstrating proper counselling techniques to motivate patients to accept a trial smoking cessation. These cases were used to stimulate discussion among the residents about barriers to confronting, motivating, or counselling nicotinedependent patients. The overall goals of the workshop were 1) to inform residents about the role of the family physician in smoking cessation, 2) to demonstrate and teach skills directed at smoking cessation, and 3) to motivate residents to assist their patients in the difficult task of becoming non-smokers. Residents were not told that their behaviour relative to counselling smoking patients would be evaluated, nor were they given specific direction on how to record such counselling activities, beyond the SOAP process currently in use in the Family Practice Centre. The SOAP process includes Subjective information from the patient, Objective information about the patient's condition, an Assessment of the patient's condition by the physician, and the physician's diagnostic and therapeutic Plan.

In a different session, clinic staff, including nurses, were presented with a shorter version of the material, in order to prepare them to identify smoking patients. Immediately after the workshop, a chart stamp was added to the patient check-in database to alert residents to ask patients about their smoking status. While taking the patients' vital signs, nurses asked patients if they were smokers or had ever been smokers. If patients had quit smoking, they were asked when this had occurred. Nicotine dependency questionnaires were given to the patients who were smokers to assist the physicians in determining the appropriate level of intervention, and highly visible smoking cessation literature was placed in each patient examination room.

In March, all charts of patients seen by residents since the January workshop were examined and those showing the smoker indicator stamp set aside. Of the more than 600 charts initially examined, 114 included the smoker stamp. These 114 charts were then divided randomly into two groups of 57 each, one to provide a pre-workshop baseline group and the other to provide an experimental, postworkshop group. It was necessary to create the baseline group from patients seen following the workshop because the smoker chart stamp was not implemented until after the workshop, and no methods existed to identify smoking 
Table 1 Patient population characteristics

\begin{tabular}{|c|c|c|c|c|c|c|c|c|c|c|c|}
\hline & \multirow{2}{*}{$\begin{array}{c}\text { Total } \\
\text { patients }\end{array}$} & \multirow{2}{*}{$\begin{array}{l}\text { Age range } \\
\text { (years) }\end{array}$} & \multicolumn{2}{|c|}{ Sex } & \multicolumn{4}{|c|}{ Race } & \multicolumn{3}{|c|}{ Resident } \\
\hline & & & $F$ & $M$ & $C$ & $B$ & $H$ & $N I$ & $Y 1$ & $Y 2$ & $Y 3$ \\
\hline Pre-workshop & 46 & $\begin{array}{c}15-70 \\
(\text { mean }=44)\end{array}$ & 33 & 13 & 25 & 2 & 15 & 3 & 4 & 17 & 25 \\
\hline $\begin{array}{l}\text { Two-months } \\
\text { post-workshop }\end{array}$ & 57 & $\begin{array}{c}14-84 \\
(\text { mean }=43)\end{array}$ & 37 & 20 & 26 & 2 & 15 & 9 & 4 & 26 & 27 \\
\hline $\begin{array}{l}\text { Six-months } \\
\text { post-workshop }\end{array}$ & 46 & $\begin{array}{c}16-82 \\
(\text { mean }=44)\end{array}$ & 29 & 17 & 22 & 5 & 13 & 6 & 4 & 20 & 22 \\
\hline
\end{tabular}

Abbreviations : $\mathrm{F}=$ Female $; \mathrm{M}=$ Male $; \mathrm{C}=$ Caucasian $; \mathrm{B}=$ Black $; \mathrm{H}=$ Hispanic $; \mathrm{NI}=$ Not indicated on chart $\mathrm{Y}=\mathrm{Year}$.

Table 2 Percentage of charts that indicated physician intervention behaviour

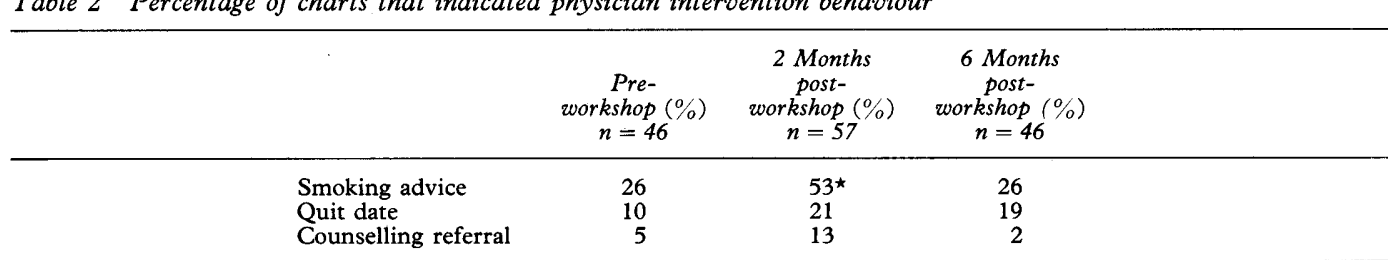

* Statistically significant at the $\mathrm{p}=0.001$ level $\left(\chi^{2}\right.$ test $)$.

patients before January. To ensure that the baseline cohort included only patients also seen before the workshop, charts of 11 new patients were excluded from the group, leaving 46. As the study sought to assess the performance of the entire practice, efforts were not made to include the same number of charts per doctor. However, the patient population characteristics and the number of charts included for each level of resident experience were consistent for the two groups (as shown in table 1).

In June, charts of smoking patients new to the practice since the last chart audit - those first seen five to six months after the initial workshop - were again identified $(n=46)$. As before, the patients' demographics and residents' level of training were very similar for each group (see table 1), and again, no specific efforts were made to look at the responses of individual residents. Rather, the objective was to compare the overall activities of the resident practice six months following the workshop with the baseline patient cohort.

A retrospective chart review was performed to analyse all three groups: patients seen prior to the workshop ( $n=46$ ), patients seen during the first two months after the workshop ( $\mathrm{n}=$ 57), and patients seen five to six months after the workshop $(n=46)$. For the charts of patients in the pre-workshop baseline group, the investigator read the assessment portions and progress notes of every chart, looking for evidence of counselling or referral that might have occurred in the 12 months prior to the workshop. Charts of patients in the two experimental groups were read to assess postworkshop physician behaviour.

Three responses were selected as evidence of physician intervention to promote smoking cessation: 1) presenting smoking cessation advice; 2) establishing a quit date; and 3) referring the patient for psychological counselling with a departmental faculty member. These three responses were chosen to determine the residents' degree of understanding of smoking cessation counselling techniques and their willingness to intervene in progressively more difficult ways. The data were analysed using a Pearson Chi-Square Test.

\section{Results}

Chart reviews indicated that, immediately following the workshop, the resident physicians were sensitive to their patients' smoking status and tended to recommend smoking cessation. Fifty-three percent of the charts of smoking patients evaluated two months postworkshop indicated that physicians had offered smoking advice at least once in that two-month period, compared with only $26 \%$ of charts for the baseline group that reflected such advice in the year preceding the workshop, a statistically significant difference $\left(\chi^{2}=\mathrm{p}<0.001\right)$. The charts also showed that residents were more likely to establish a quit date and suggest psychological counselling for their twomonths-post-workshop patients than for those seen before the workshop. The differences were not statistically significant, however (quit date [ $<<0.085]$; psychological referral $[p<0.1491])$.

Nevertheless, the residents' initial awareness of smoking status and cessation advice lessened over time. When the pre-workshop patient group was compared with the group seen six months following the workshop, none of the three variables showed significant differences. Exactly the same number of charts indicated that physicians offered smoking advice and more showed that physicians suggested a quit date, but fewer charts showed that physicians made psychological referrals than before the workshop (see table 2).

\section{Discussion}

The results of this study indicate that a single three-hour training workshop on cigarette cessation counselling techniques and the presence of a chart prompt stamp are enough to bring about a short-term change (covering at least two months) in resident practice be- 
haviour with smoking patients. This finding is consistent with other studies that demonstrate residents' ability to learn these counselling skills. $^{3,11,18,19}$ Our findings further confirm those of McIlvain et al. that a brief training programme and chart prompting system are not sufficient to produce a sustained effect in resident counselling behaviour. ${ }^{20}$

Even though the resident physicians were aware of the health hazards of cigarette smoking and understood different techniques to assist their patients in smoking cessation, they did not apply these techniques in their practice over a sustained period of time. This finding is consistent with a study of physician compliance that concludes: "knowledge of recommendations, perception of compliance and belief in the importance of preventive medicine activities have been found to be misleading predictors of performance, ${ }^{\prime 2}$ as noted in an earlier study by Sanson-Fisher. ${ }^{21}$

Possible reasons for physicians' failure to implement their knowledge of smoking cessation strategies include physicians' attitudes, such as unjustified optimism as to the immediate impact of their advice, or the reverse - unjustified pessimism as to patients' willingness to follow physician advice. Young physicians, trained to value aggressive treatment, may also question the effectiveness of simple verbal intervention such as offering smoking advice. Other reasons may be due to inefficiencies in the systems that support the practice. For example, the time necessary for advice and discussion may discourage physician intervention, especially for the more difficult tasks of establishing a quit date or arranging for psychological counselling. Nurses' failure to identify patients who smoke may be another reason. Yet another possibility, of course, is that residents simply forget to incorporate their newly learned strategies.

There are several limitations to this study. First, the system created to identify and monitor smoking patients was implemented concurrently with the study, and thus there was not sufficient time before the study period commenced to eliminate any problems with the system itself. For example, it is likely that more of the 600-plus patients seen by residents from January to March were smokers whose status was not properly identified on their charts. The additional charts would have characterised the practice more completely. Second, because the study considered physician behaviour across the practice and did not specifically include the same number of charts for each doctor in each patient group, it is also possible that diligent residents were overrepresented at 2 months and under-represented at 6 months. Third, the study did not attempt to assess the effectiveness of the workshop itself; a different approach might have yielded more statistically significant results than the present study. Fourth, the study assumed that if the specific physician behaviour under investigation was not recorded in the patient charts, it did not occur. Clearly, the oversight may have been in recording rather than in doing, but the effort here was to standardise the study by following an agreed protocol. Finally, the effort to assess resident practice in a natural setting precluded using a randomized controlled trial design.

McIlvain et al. rightly point out that training, teaching methods, and curricula, as well as systems issues (such as resident workload and support for counselling behaviour), must be addressed further in the quest for effective ways to train physicians to help patients stop smoking. ${ }^{20}$ Kottke and colleagues concur with the notion that positive clinic conditions and other facilitating systems significantly increase the rate of physician intervention. ${ }^{22}$

Thus, the implications of this study point to system support within a practice, whether comprised of residents or practising physicians, that promotes a specific intervention protocol. Long-term and continuous physician intervention that will ultimately produce successful patient treatment must include regular training of nurses and involve receptionists and medical transcriptionists, as well as physicians. It must identify smokers consistently and make intervention an obvious and expected behaviour.

Further studies are needed in which educational workshops are combined with techniques of quality assurance and which incorporate continuing rewards or reinforcements for effective physician behaviour. For example, the practice could establish appropriate practice indicators, then perform an audit of smoking patients' charts. The results of the chart audit are analysed and tabulated for physician review. Should the intervention be less than expected or established, then additional educational approaches would be provided or system improvements sought. ${ }^{23}$ Chart audits could be performed on a monthly basis, and results reported to the group to assist physicians in incorporating new practice skills.

This study confirms that physicians' intellectual acceptance of the concept of health promotion is not adequate for implementation $;^{2}$ physicians must incorporate health promotion techniques into their standard patient care behaviour pattern in order to achieve a performance level that matches their beliefs about health promotion.

I would like to acknowledge the work of Betsy Goebel Jones of the Department of Family Medicine, Texas Tech University Health Sciences Center, who assisted in the review and editing of this manuscript.

1 Wechsler H, Levine S, Idelson RK et al. The physician's role in health promotion: A survey of primary care physicians. $N$ Engl f Med 1983; 308: 97-100.

2 Pommerenke, Forrest A, Weed DL. Physician compliance: Improving skills in preventive medicine practices. $\mathrm{Am}$ Fam Pract 1991; 43.

3 Ockene JK, Quirk ME, Goldberg RJ et al. A residents' training program for the development of smoking training program for the development of smoking

4 Cohen SJ, Stookey GK, Katz BP, Drook CA. Encouraging primary care physicians to help smokers quit. A random ized controlled trial. Ann Intern Med 1989; 110 : 548-52.

$5 \mathrm{Li} \mathrm{VC,} \mathrm{Kim} \mathrm{YJ,} \mathrm{Ewart} \mathrm{CK} \mathrm{et} \mathrm{al.} \mathrm{Effects} \mathrm{of} \mathrm{physician}$ counseling on the smoking behaviour of asbestos-exposed workers. Prev Med 1984; 13 : 462-76.

6 Peto R, Lopez AD, Boreham J, Thun M, Heath C. Mortality from tobacco in developed countries: indirect estimation from national vital statistics. Lancet 1992; 
7 Orleans CT. Understanding and promoting smoking cessation; Overview and guidelines for physician intervention. Annu Rev Med 1985; 36: 51-61

8 Canadian Task Force. Canadian Task Force on periodic health examination: The periodic health examination. Can Med Assoc J 1979; 121: 1198-254.

9 Anda RJ, Remington PL et al.. Are physicians advising smokers to quit? The patients' perspective. $\mathcal{F} A M A 1987$; 257: 1916-9.

10 Cohen SJ, Christen AG, Katz PG, Drook CA, Davis BJ, Smith DM. Counseling medical and dental patients Smith DM. Counseling medical and dental patients about cigarette smoking: The impact of nicotine gum and

11 Campbell EE, Villagra VG, Rogers C et al. Teaching and promoting smoking cessation counseling in primary care residencies : Description of a method. Teach and Learn in Med 1991; 3: 20-7.

12 Husten CG, Manley MW. How to help your patients stop smoking. Am Fam Physician 1990; 42: 1017-26.

13 Janrozik K, Vesseg M, Fowler G et al. Controlled trial of three different anti-smoking interventions in general practice. BMF 1984; 288 : 1499-503.

14 Wilson DM, Taylor DW, Gilbert JR et al. A randomized trial of family physician intervention for smoking cessation. IAMA 1988; 260: $1570-4$.

15 Kottke TE, Battista RN, Defriese GH et al. Attributes of successful smoking cessation interventions in medical practice: a meta-analysis of 39 controlled trials. $\mathcal{F} A M A$ 1988; 259: 2883-9.

16 Doctors Ought to Care. How to get involved: Organizing a DOC chapter. DOC News and Views 1992; 7(1): 13.

17 American Academy of Family Physicians. AAFP stop smoking kit. Kansas City, MO : 1989.

8 Quirk ME, Ockene JK, Kristellar J et al. Training family practice and internal medicine residents to counsel patients who smoke: Improvement and retention of counseling skills. Fam Med 1991; 23 : 108-11.

19 Strecher VG, O'Malley MS, Villagra VG. Can residents be trained to counsel patients about quitting smoking? Results from a randomized trial. F Gen Intern Med 1991; 6: $9-17$.

20 McIlvain HE, Susman JL, Manners MA, Davis CM, Gilbert CS. Improving smoking cessation counseling by Gilbert CS. Improving smoking cessation counseling by 21 Sanson-Fisher R, Fairbairn S, Maguire P. Teaching skills in communication to medical students: A critical review of methodology. Med Educ 1981; 15: 33-7.

22 Kottke TE, Solberg LI, Brekke ML, Conn SA, Maxwell P Brekke MJ. A controlled trial to integrate smoking cessation advice into primary care practice: Doctors helping smokers, round III. F Fam Pract 1992; 34 $701-8$.

23 Donabedian A. The quality of care - how can it be assessed ? fAMA $1988 ; 260$ : $1743-8$.

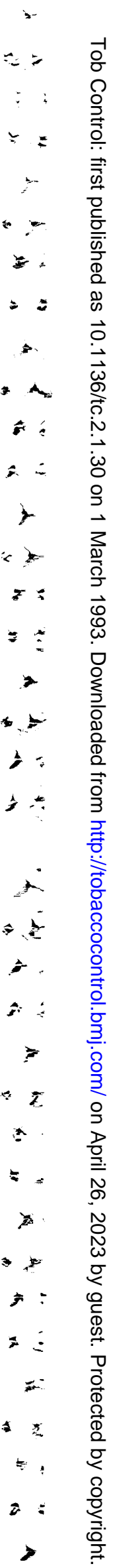

$+x$

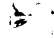

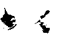

